\title{
Ontogenetic variations of the head of Aptenodytes forsteri (Aves, Sphenisciformes): muscular and skull morphology
}

\author{
María Alejandra Sosa ${ }^{1}$ - Carolina Acosta Hospitaleche ${ }^{1,2}$
}

Received: 22 March 2017/Revised: 13 July 2017/Accepted: 14 July 2017/Published online: 22 July 2017

(C) Springer-Verlag GmbH Germany 2017

\begin{abstract}
The emperor penguin (Aptenodytes forsteri) is the largest extant penguin among living species breeding in winter, at Antarctic high latitudes. Despite several studies made on this species, musculature and skeletal anatomy are barely known, especially in non-adult specimens. To address this shortfall, dissections and comparative descriptions were made on crania and mandibles of individuals of different ontogenetic stages: chicks, juveniles, and adults. The results presented here show significant differences in musculature between the age groups, and the proportions between bill and cranium also change along postnatal ontogeny.
\end{abstract}

Keywords Anatomy $\cdot$ Cranium-mandible $\cdot$ Head muscles · Ontogeny $\cdot$ Spheniscidae $\cdot$ Antarctica

\section{Introduction}

The emperor penguin Aptenodytes forsteri Gray, 1844 (Aves, Sphenisciformes) has a circumpolar distribution restricted to Antarctica. It is the largest penguin regarding size and weight among current species, reaching $1.20 \mathrm{~m}$ height and $45 \mathrm{~kg}$ weight (Martínez 1992). It is listed as near threatened (NT) according to IUCN, estimating that within the next three generations, its population will decline rapidly

Carolina Acosta Hospitaleche

acostacaro@fcnym.unlp.edu.ar

María Alejandra Sosa

alesosa_15@hotmail.com

1 División Paleontología Vertebrados, Facultad de Ciencias Naturales y Museo, Museo de La Plata, Paseo del Bosque s/n, B1900FWA La Plata, Argentina

2 CONICET, Buenos Aires, Argentina due to climate change. However, the status of current populations remains stable (BirdLife International 2012).

The emperor penguin is a species of marine and pelagic habits, feeding mainly on fish, but krill and cephalopods are also included in its diet (Klages 1989; Wienecke and Robertson 1997; Cherel and Kooyman 1998). A. forsteri is the only species that breeds and has an annual reproductive cycle which is well known (Stonehouse 1953; Prévost 1961; Isenmann and Jouventin 1970; Jouventin 1971).

Little is known about details of the osteo-muscular anatomy of A. forsteri (Sclater 1888; Zusi 1975; Saiff 1976; Welsch and Aschauer 1986; Osa et al. 1993); therefore any additional information is extremely valuable. The life cycle, together with its distribution at high latitudes, partly explains the scarceness of anatomical studies, particularly in the case of chicks and juveniles where samples are difficult to collect. In our study, the musculature and osteology of the cranium and mandible were compared among individuals of different ages, including chicks, juveniles, and adults, with the aim of improving the knowledge about $A$. forsteri anatomy.

\section{Materials and methods}

Crania and mandibles were collected by members of the Instituto Antártico Argentino (IAA) in Snow Hill Island (West Antarctica) during summer field trip of 2014. They are deposited in the Ornithology section of the Museo de La Plata (MLP-O), Argentina. Other skeletons consulted belong to the Naturhistoriska Riksmuseet (Nr), Sweden, and the Natural History Museum (NHM) in Tring, United Kingdom. Specimens were classified into the age categories: chicks $(n=9)$, juveniles $(n=2)$, and adults $(n=2)$ following (Stonehouse 1953) (Table 1). 
According to the available material, chicks and juveniles were dissected, identifying major muscle groups, and described from the most superficial to the deepest layers. The muscles in the adult were compared from Zusi (1975). Then, each cranium and mandible was prepared for osteological comparisons.

The descriptions follow Baumel et al. (1993), supplemented by George and Berger (1966), Zusi (1975), and Livezey and Zusi (2006) when necessary. Measurements were taken with a Vernier Caliper in increments of $0.1 \mathrm{~mm}$.

\section{Results}

\section{Comparative osteology}

\section{Cranium}

In adults, the occipital region has a quadrangular shape in occipital view (Fig. 1a), while it is triangular in juveniles (Fig. 1b). All the elements that form this region are fused in both cases. On the contrary, this region does not have a definite shape in chicks (Fig. 1c), and all its elements are individualized as independent structures.

The Os supraoccipitale is completely developed in the adult, but in juveniles it has an unossified dorsal longitudinal line (Fig. 1b), which is larger in chicks. The $O s$ epioticum is observed at both sides of the Os supraoccipitale in chicks. The fusion degree between the Os epioticum and the $O$ s supraoccipitale varies among specimens delimiting the foramen veni occipitalis externae (Fig. 1c).

The Ossa exoccipitale, at both sides of the condyle occipitale are individualized in chicks. In both, juvenile and adults, the Ossa exoccipitale constitute the processi paraoccipitale. These triangular processes are projected ventrolaterally, surpassing the processi mediale parasphenoidale in adults (Fig. 1a). The processi mediale parasphenoidale have angular outlines which are equally projected in juveniles (Fig. 1b). These processes are not yet defined in chicks, where the area remains cartilaginous (Fig. 1c).

Table 1 Measurements (in $\mathrm{mm}$ ) taken on the crania and mandibles of Aptenodytes forsteri

\begin{tabular}{|c|c|c|c|c|c|c|c|c|c|c|c|}
\hline & \multicolumn{8}{|l|}{ Chicks } & \multirow{2}{*}{$\begin{array}{l}\text { Juvenile } \\
\text { MLP-O- } \\
15035\end{array}$} & \multicolumn{2}{|l|}{ Adults } \\
\hline & $\begin{array}{l}\text { MLP-O- } \\
15026\end{array}$ & $\begin{array}{l}\text { MLP-O- } \\
15027\end{array}$ & $\begin{array}{l}\text { MLP-O- } \\
15028\end{array}$ & $\begin{array}{l}\text { MLP-O- } \\
15029\end{array}$ & $\begin{array}{l}\text { MLP-O- } \\
15030\end{array}$ & $\begin{array}{l}\text { MLP-O- } \\
15031\end{array}$ & $\begin{array}{l}\text { MLP-O- } \\
15032\end{array}$ & $\begin{array}{l}\text { MLP-O- } \\
15033\end{array}$ & & $\begin{array}{l}\text { NHM } \\
1846.4 .15 .28\end{array}$ & $\begin{array}{l}\text { NHM } \\
1846.4 .15 .26\end{array}$ \\
\hline $\mathrm{C}$ & 30.6 & 30.0 & 30.4 & 29.6 & 29.6 & 26.4 & 29.8 & 21.0 & 75.5 & 88.8 & 85.3 \\
\hline $\mathrm{BH}$ & 08.0 & 07.2 & 07.0 & 08.2 & 08.3 & 07.7 & 07.6 & 07.4 & 12.2 & 17.7 & 25.1 \\
\hline BW & 16.0 & 14.0 & 16.4 & 16.5 & 15.5 & 08.7 & 13.0 & 10.0 & 30.0 & 39.1 & 42.1 \\
\hline NL & 16.1 & 16.8 & 15.3 & 18.0 & 15.6 & 14.2 & 16.9 & 14.3 & 33.0 & 60.9 & 25.2 \\
\hline PrW & 09.0 & 09.4 & 07.8 & 09.6 & 10.7 & 08.6 & 09.6 & 07.2 & 19.4 & 25.2 & 30.8 \\
\hline IW & 08.9 & 08.1 & 09.9 & 08.9 & 10.2 & 08.4 & 07.4 & 06.4 & 13.2 & 19.2 & 25.7 \\
\hline PoW & 35.3 & 32.2 & 31.8 & 34.4 & 34.6 & 29.9 & 31.2 & 29.6 & 55.6 & 69.7 & 73.8 \\
\hline FGL & 27.1 & 26.0 & 24.7 & 30.4 & 29.8 & 24.1 & 26.7 & 25.5 & 49.8 & 55.8 & 58.1 \\
\hline FGW & 06.5 & 05.7 & 04.5 & 06.1 & 07.0 & 04.9 & 05.8 & 05.5 & 11.2 & 09.5 & 10.8 \\
\hline $\mathrm{SH} \quad \mathrm{Cr}$ & 22.3 & 16.3 & 18.6 & 17.5 & 20.9 & 20.3 & 20.0 & 16.0 & 38.4 & ca. 35.4 & ca. 30.1 \\
\hline $\mathrm{Ca}$ & 30.2 & 26.5 & 25.2 & 26.3 & 27.5 & 23.9 & 27.2 & 21.8 & 42.5 & ca. 50.5 & ca. 52.5 \\
\hline FMW & 10.6 & 09.0 & 09.5 & 10.2 & 10.1 & 08.6 & 10.3 & 09.3 & 15.9 & - & 15.8 \\
\hline FMH & 06.8 & 06.2 & 04.8 & 05.6 & 06.7 & 10.0 & 06.4 & 05.0 & 12.8 & - & 11.7 \\
\hline $\mathrm{CW}$ & 03.9 & 04.4 & 04.0 & 04.2 & 03.9 & 03.3 & 04.3 & 01.7 & 09.3 & - & 08.8 \\
\hline $\mathrm{CH}$ & 03.3 & 03.2 & 02.8 & 03.2 & 03.3 & 2.7 & 03.1 & 02.1 & 05.0 & - & 04.5 \\
\hline $\mathrm{TL}$ & 74.4 & 72.4 & 71.2 & 75.7 & 75.3 & 64.6 & 70.9 & 66.0 & 155.6 & 180.2 & 178.6 \\
\hline CL & 65.4 & 65.7 & 64.0 & 68.8 & 65.9 & 57.3 & 64.4 & 58.6 & 150.4 & 179.6 & - \\
\hline ML & 61.3 & 61.5 & 60.4 & 64.8 & 61.9 & 53.0 & 59.7 & 53.5 & 141.8 & 176.4 & 15.7 \\
\hline MH & 05.8 & 04.9 & 05.2 & 05.7 & 05.9 & 04.7 & 05.0 & 05.0 & 11.2 & 15.7 & 15.9 \\
\hline
\end{tabular}

Only complete specimens were measured

$C$ culmen length, $B H$ bill height, $B W$ maximum width of the bill, $N L$ apertura nasi ossea length, $\operatorname{Pr} W$ preorbital width taken at the $O s$ lacrimale level, $I W$ interorbital minimum width taken dorsally, PoW width taken at the level of the processus postorbitalis, FGL length of the fossa glandulae nasalis, distance measured from the Os lacrimale to the processus postorbitalis, FGW maximum width of the fossa glandula nasale, $\mathrm{SH}$ height of the cranium ( $\mathrm{Cr}$ taken at the contact between the $\mathrm{Os}$ frontale and the processus frontalis nasalis, $\mathrm{Ca}$ taken in the point of maximum height), FMW width of foramen magnum, FMH height of foramen magnum, $\mathrm{CW}$ width of condylus occipitalis, $\mathrm{CH}$ height of condylus occipitalis, $T L$ total length of the cranium, $C L$ length of the cranium taken from the condylus occipitalis to the tip of the bill, $M L$ length of the ramus mandibulae, $M H$ height of the ramus mandibulae taken caudally to the fenestra rostralis mandibulae 
Fig. 1 Crania of Aptenodytes forsteri in occipital view showing the main features compared in the text: a adult, b juvenile, c chick (a)



(b)

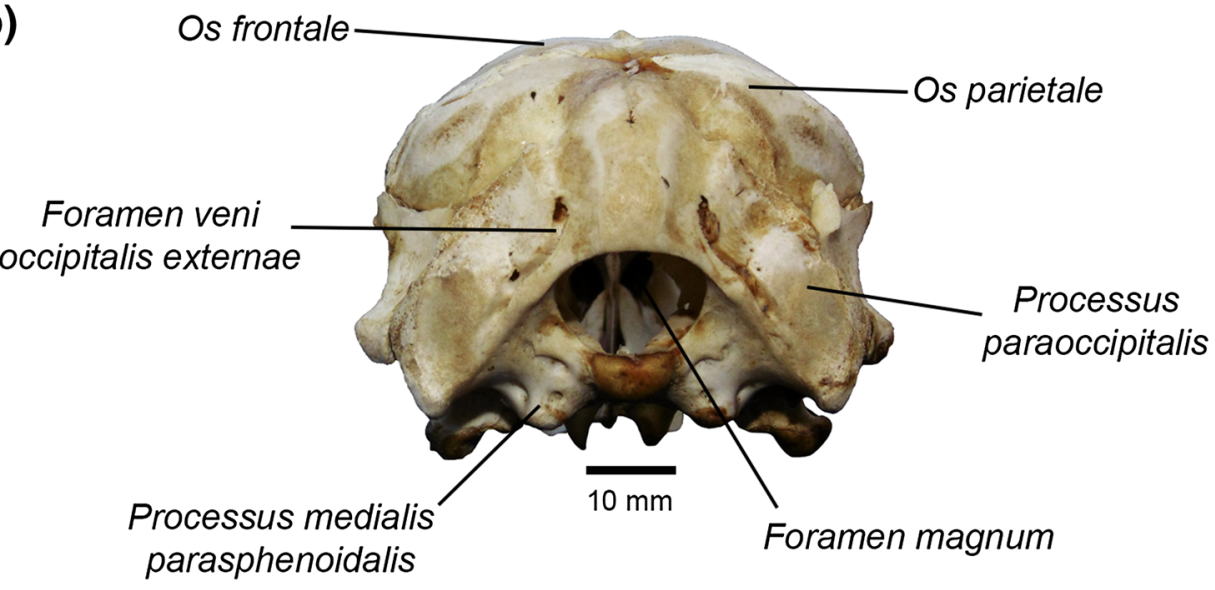

(c)

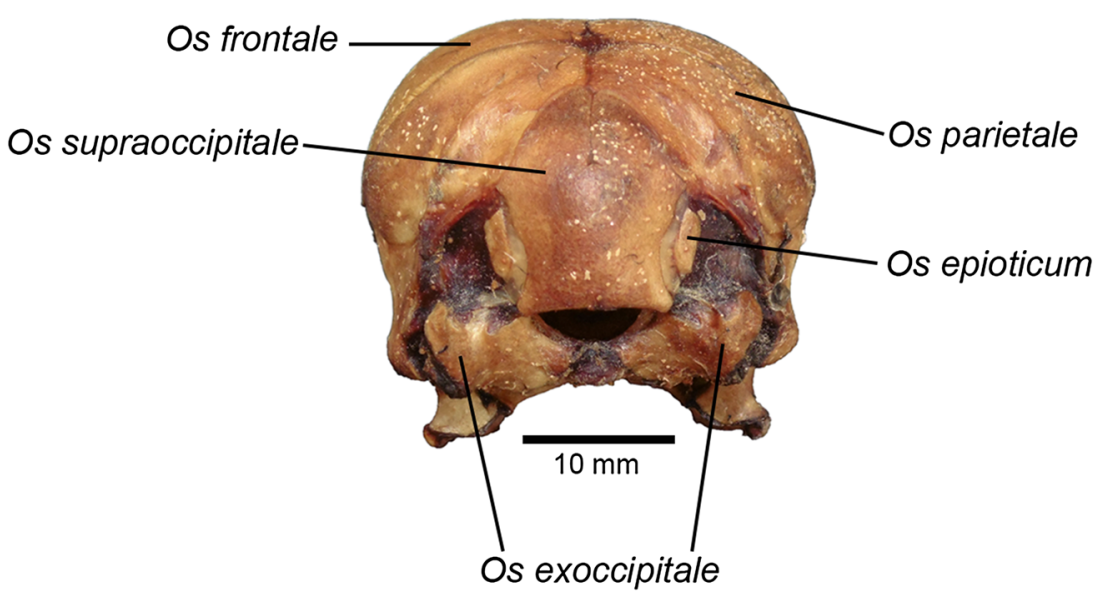

The foramen magnum presents an uninterrupted sub-circular outline in all ontogenetic stages examined. The condylus occipitalis, constituted by the Os basioccipitalis, is kidney shaped, with a pronounced incisura mediana condyli in the adults, which is less conspicuous in the juveniles. In chicks, the condylus occipitalis is not defined or, in some cases, is very small, oval shaped, and without the typical incisura mediana condyli that appears in juveniles (Fig. 1).

The Os supraoccipitale, Ossa parietale, Ossa frontale, and processus frontalis nasalis are fused in the adult, whereas the joins are still visible in juveniles and chicks (Fig. 2). An unossified area of variable extension appears between the Ossa parietale and the Ossa frontale in all chicks, with increasing ossification of the cranial roof. This opening is completely closed in juveniles.

The prominentia cerebellaris, formed by the Os supraoccipitalis, is projected caudally beyond the occipital region, both in adults and juveniles (Fig. 2a, b). In the chick, this caudal projection does not differ as a separate structure or it is poorly differentiated (Fig. 2c). 
The Ossa frontale have a triangular shape, covering a large area of the cranial roof in chicks (Fig. 2c). The fossae glandulae nasale reach their major development in adults, and the Ossa frontale cover a proportionally smaller surface.

In all stages the fossae glandulae nasale begin on the $O s$ lacrimale and extend caudally to the processi postorbitale, widening caudally (Fig. 2). There is not a supraorbital edge, the fossa remains laterally open, and only a welldefined rim runs medially.

In the adult, the fossae glandulae nasale are fenestrated and projected ventrolaterally at the cranial-most end. In the juvenile, the fossae glandulae nasale have a notable medial ridge in their rostral portion that becomes weaker caudally (Fig. 2b). The fossae glandulae nasale are still cartilaginous in chicks (Fig. 2c), and only a marked ridge in the rostral half of each fossa is observed. The Os frontale constitute a sagittal ridge, which is proportionally broader in the adults than in the juveniles and chicks.

The processi postorbitale are projected laterally in the adult (Fig. 2a), whereas in juveniles and chicks (Fig. 2b, c) they are not developed and the portion of the $O s$ laterosphenoidale that contribute to their formation, remains cartilaginous.

The processi frontale premaxillare are parallel to each other up to the contact area with the processi frontale nasale. A similar condition is shared with juveniles and chicks.

The lateral wall of the braincase is completely fused in adults (Fig. 3a). On the contrary, in juveniles and chicks, the
Fig. 2 Crania of Aptenodytes forsteri in dorsal view, displaying the elements described in the text: a adult, b juvenile, $\mathbf{c}$ chick

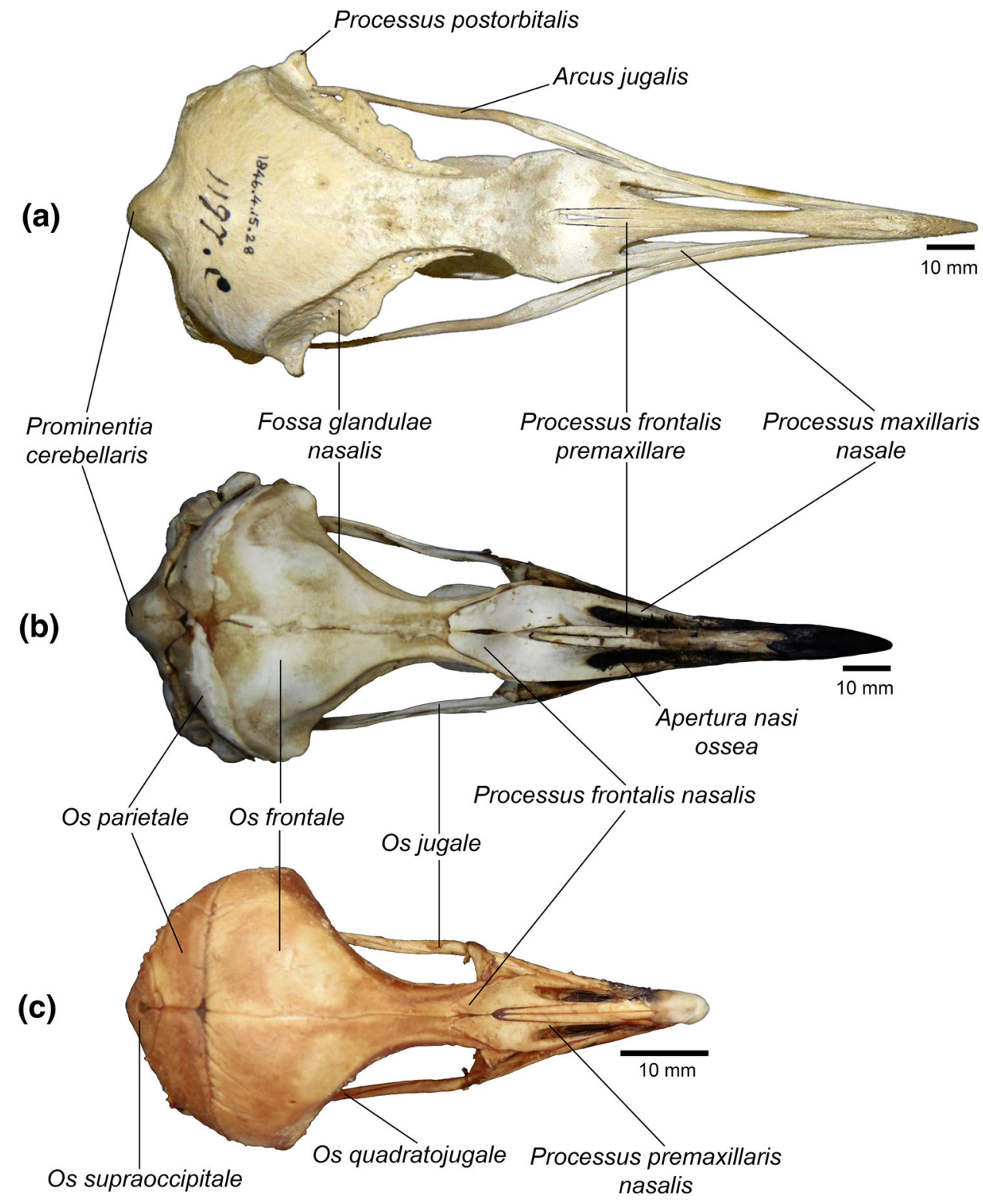


Os supraoccipitale, Os quadratum, Os parietale, Os laterosphenoidale, and Os frontale are observed as independent elements (Fig. 3b, c). What is more, in chicks, a portion between the $O s$ parietale, Os frontale, $O s$ laterosphenoidale, and $O s$ squamosus remains cartilaginous.

The crista nuchalis temporalis and the crista nuchalis transversa are well developed in the adult, although they are not conspicuous structures (Fig. 3a). The crista temporalis is not developed in juveniles because the Os parietale and the $O s$ frontale are not fused and the crista nuchalis transversa is being sketched (Fig. 3b). None of these cristae are defined in chicks (Fig. 3c).

In the adults, the fossa temporalis is delimited rostrally by the crista temporalis and caudally by the crista nuchalis transversa (Fig. 3a). Its dorsal edge is sharp and does not reach the sagittal line. This fossa is shallow and presents a convex wall, following the contour of the cranium, becoming slightly deeper toward its caudal portion. In juveniles and chicks, the fossa temporalis is not differentiated in the lateral wall of the cranium (Fig. 3b, c).

The Ossa frontalia are convex in all their extension, this convexity is stronger in juveniles and even more in chicks, determining a globus braincase. The rostral portion of the Os frontale descends toward the contact to the Os lacrimale and the processus nasalis frontalis.

The Os mesethmoidale is ossified in adults, forming the septum interorbitale (Fig. 3a). Only the rostral portion is ossified in juveniles (Fig. 3b), whereas this area remains totally cartilaginous in chicks (Fig. 3c).

The sigmoid arcus jugalis is constituted by the fusion of the processus jugalis of the Os maxillare, Os jugale, and Os quadratojugale in adults. All these bones are unfused in juveniles and chicks, appearing as separate elements. The ventral curvature surpasses the lamina parasphenoidalis in
Fig. 3 Crania of Aptenodytes forsteri in lateral right view, elements compared are pointed out: a adult, b juvenile, $\mathbf{c}$ chick

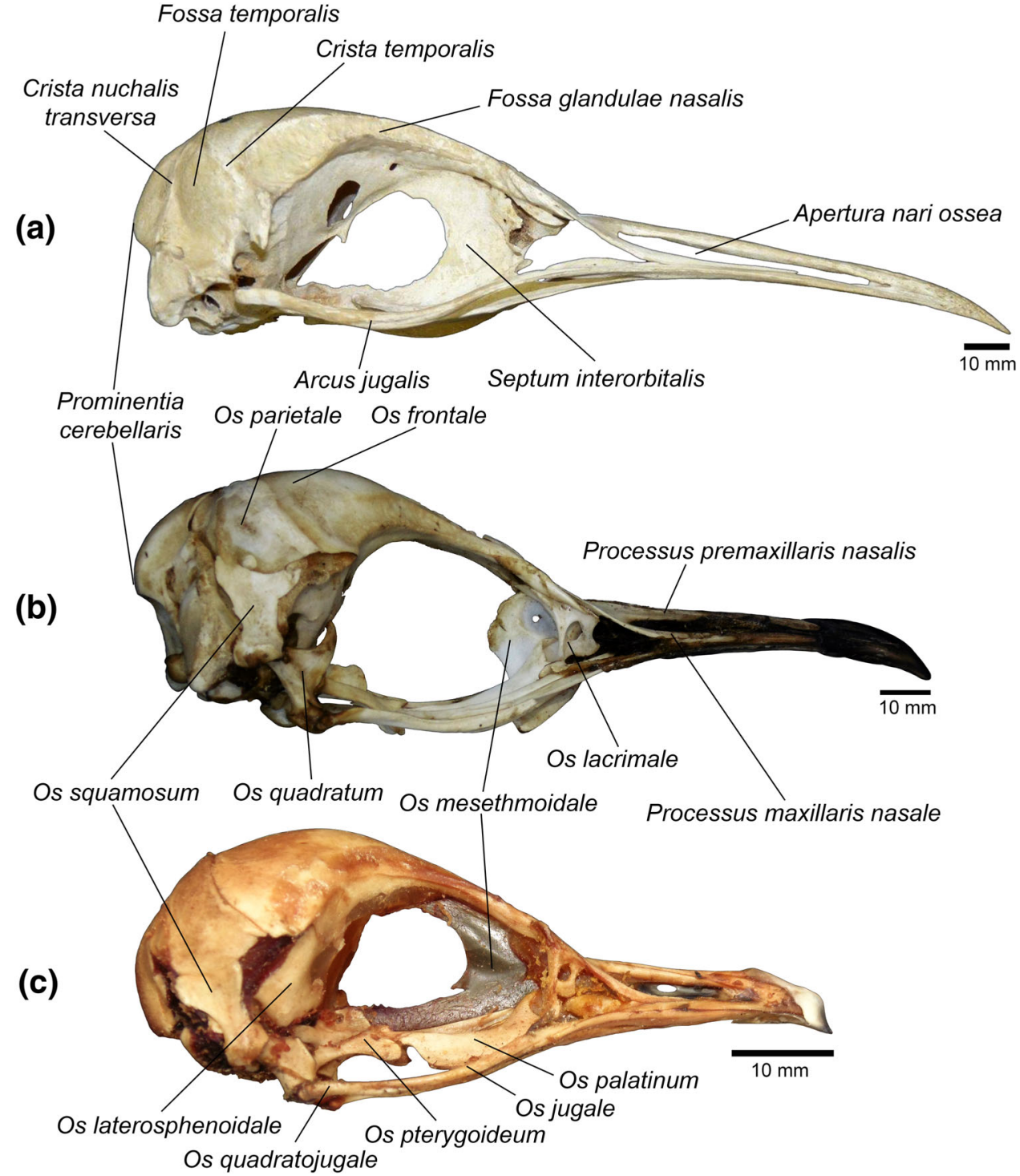


adults (Fig. 3a) and it is less pronounced in juveniles and chicks (Fig. 3b, c).

The rostrum is formed by the fusion of the Ossa premaxillaria, Ossa maxillaria, and Ossa nasalia in adults, constituting approximately one half of the total length and height of the cranium (see Table 1). These proportions are clearly different in juveniles and chicks, in which the rostrum is proportionally smaller.

The apertura nasi ossea are elongated and constant in width. They open laterally at the rostral portion, and dorsally at the caudal end. These openings are proportionally shorter in chicks.

The base of the cranium is constituted by the complete fusion of elements in adults and juveniles, whereas the $O s$ basioccipitale, Os exoccipitale, Os parasphenoidale, and rostrum parasphenoidale are still independent elements in chicks. The rostrum parasphenoidale is proportionally larger in adults than in juveniles and chicks, extending rostrally until it contacts with the Os pterygoideum and $O s$ palatinum.

The Os pterygoideum widens rostrally in adults and juveniles, forming the pars palatina (Fig. 4a, b). In chicks, these bones have a marked concavity at their lateral margin (Fig. 4c). The Os palatinum is flattened in the adult, with the pars lateralis well developed. A similar condition is observed in juveniles, whereas in chicks the Os palatinum has a similar width throughout, but the pars lateralis does not extend laterally.

The Os quadratum is similarly developed in adults and juveniles (Fig. 5g, h). The corpus ossi quadrati connects with the processus oticum, processus orbitalis, and processus mandibularis, which are all ossified. The processus oticum is projected laterally and articulates dorsally with the Os squamosum. The capitulum oticum and capitulum squamosum are well defined, separated by the incisura intercapitularis. The slender and rectangular processus orbitalis projects dorsomedially. The strong processus mandibularis projects ventrally, and presents a condylus pterigoideus, a condylus medialis, and a condylus caudalis well developed. The foramen pneumaticum is constituted by a very small opening observed in caudomedial view, between the processus orbitalis and the processus mandibularis. In chicks, the Os quadratum has the corpus Ossi quadrati well ossified, the processus oticum and the processus mandibularis only partially ossified, and the processus orbitalis cartilaginous.

\section{Mandible}

Each ramus is curved caudoventrally at its middle part, and both ends are straight in adults (Fig. 5b). This curvature is smaller in juveniles (Fig. 5d) and the rostral third is inclined ventrally, producing a sigmoid shape. In chicks, the jaw is almost straight (Fig. 5f), the curvature is minimal and the rostral portion is directed ventrally.

All the elements of the rami, i.e., Os dentale, Os prearticular, Os coronoideum, Os spleniale, Os supra-angulare, and Os articulare are still individualized in juveniles and chicks (Fig. 5). In adults they are almost completely fused (Fig. 5a, b).

The fenestra caudalis mandibularis and the fenestra rostralis mandibularis open laterally. The first one has a rounded contour in adults (Fig. 5b) and an oval one in juveniles and chicks (Fig. 5d, f), with its major axis craniocaudally developed. The fenestra rostralis mandibularis is elongated, with the major axis parallel to the edges of the mandible in all of the stages analyzed, including in the chick.

The processus retroarticularis is projected caudoventrally only in the adult (Fig. 5a, b); in juveniles it is placed at the same plane as the rami (Fig. 5c). The incisura retroarticularis is well developed in adults and juveniles. The complete articular region remains cartilaginous and indistinguishable in chicks (Fig. 5e, f), and only the processus retroarticularis is barely developed and projected caudally.

The processus coronoideus, located dorsally in relation to the rostral border of the fenestra caudalis mandibularis, is presented as an outstanding structure in the adult (Fig. 5b), whereas in the juvenile it appears as a scarcely marked ridge and it is absent in chicks. Even though the cotyla medialis, cotyla lateralis, and cotyla caudalis are well defined in adults, they are hardly differentiated in juveniles (Fig. 5a, c). Among these structures, the cotyla medialis develops first in early stages.

\section{Comparative myology}

\section{Musculus depressor mandibulae}

This muscle is divided into two parts: $M$. depressor mandibulae pars superficialis, and $M$. depressor mandibulae pars profunda (sensu Livezey and Zusi 2006). The M. depressor mandibulae pars superficialis has its origin by fleshy fibers on the Ossa parietalia, on both sides of the prominentia cerebellaris. It is directed ventrally, passes over the Os exoccipitale and inserts by fleshy fibers on the processus retroarticularis of the mandible in the chicks (Fig. 6b), whereas in the juveniles, it passes on the lateral surface of the processus paraoccipitale and inserts by an aponeurosis on the processus retroarticularis (Fig. 6a). It is an important muscle that, although already individualized in chicks, becomes bulkier in juveniles. In chicks, the M. depressor mandibulae pars profunda (Fig. 6c) originates behind the meatus acusticus externus. It is ventrally directed and inserted by fleshy fibers on the 
Fig. 4 Crania of Aptenodytes forsteri in palatal (ventral) view, pointing out the elements described: a adult, $\mathbf{b}$ juvenile, c chick



processus retroarticularis, rostral to the insertion of the $M$. depressor mandibulae pars superficialis.

\section{Musculus adductor mandibulae externus}

It is divided into three parts in adults: $M$. adductor mandibulae externus pars rostralis, $M$. adductor mandibulae externus pars ventralis, and $M$. adductor mandibulae externus pars profunda (Baumel et al. 1993). This differentiation is not so marked in the chicks, probably because the musculature is not completely developed. Therefore, it is treated without subdivisions. It is inserted by fleshy fibers on the dorsal edge and on the lateral surface of the mandible in chicks and juveniles. This muscle is barely developed in chicks, as a very thin sheet, especially in its origin on the fossa temporalis, (Fig. 6b, c) then it is directed cranioventrally, passing under the processus postorbitalis and behind the arcus jugalis. In juveniles, the $M$. adductor mandibulae externus is notably bulkier, covering a more extensive area on the lateral wall of the cranium (Fig. 6a).

\section{Musculus pseudotemporalis superficialis}

This is an elongated and thin muscle in chicks (Fig. 6d, e) that originates in the caudal wall of the orbit, on the $O s$ 
Fig. 5 Mandibles and quadrates of Aptenodytes forsteri: mandible of a adult in dorsal view, $\mathbf{b}$ adult in lateral view, c juvenile in dorsal view, d juvenile in lateral view, $\mathbf{e}$ chick in dorsal view, $\mathbf{f}$ chick in lateral view; left quadrate of g juvenile in medial view, $\mathbf{h}$ chick in medial view
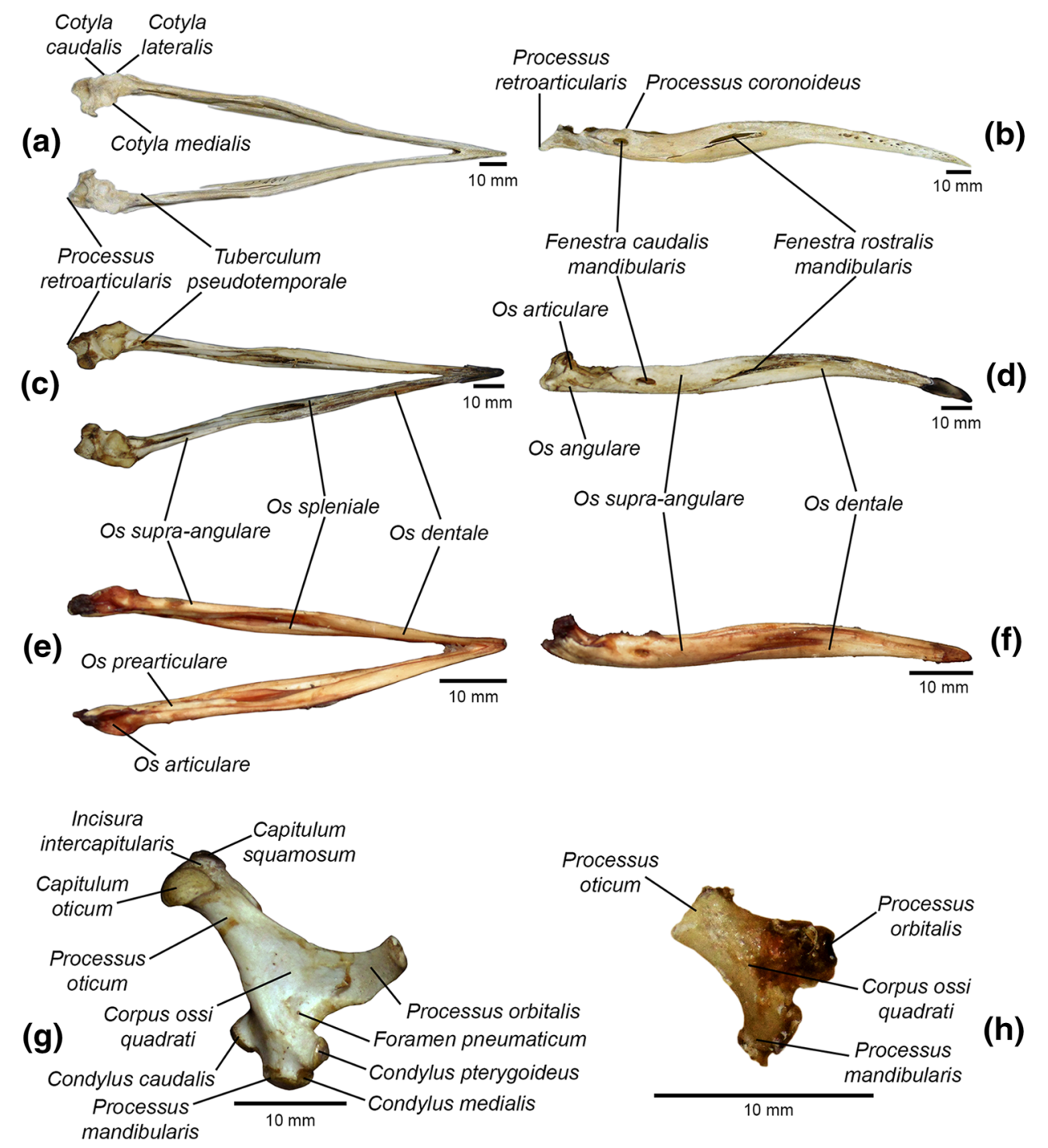

(h) laterosphenoidale, adjacent to the processus postorbitalis. It is directed ventrally to inserts through a tendon on the medial surface of the mandible, caudal to the fenestra mandibularis caudalis. In juveniles and adults, this muscle originates on the Os laterosphenoidale and inserts on the tuberculum pseudotemporale of the mandible.

\section{Musculus pseudotemporalis profundus}

Although not very large, it is already well developed in chicks (Fig. 6d, e). This muscle originates by fleshy fibers on the rostral surface of the processus orbitalis quadrati; it is directed anteroventrally and inserts into the medial surface of the mandible, rostral to the insertion of the $M$. pseudotemporalis superficialis and ventral to the insertion of the M. adductor mandibulae externus.
Musculus pterygoideus ventralis

It can be subdivided into a lateral and a medial portion in chicks (Fig. 6f). The M. pterygoideus ventralis pars lateralis originates from an aponeurosis that extends caudally along the entire lateral border of the Os palatinum. Its fibers widen caudally up to its fleshy insertion on the posteromedial portion of the mandible, behind the articulation area. In juveniles, this muscle extends ventral and laterally, and occupies part of the posterolateral region of the mandible (Fig. 6a). The M. pterygoideus ventralis pars medialis has its origin through an aponeurosis on the posteromedial border of the Os palatinum. It extends caudo-laterally on the ventral side of the Os pterygoideum, widened by fleshy fibers to be inserted on the medial border of the mandible, dorsal to the insertion of the $M$. pterygoideus ventralis pars lateralis. 
Fig. 6 Muscles of cranium and mandible of Aptenodytes forsteri: a juvenile in lateral view, $\mathbf{b}$ chick in caudo-lateral view, $\mathbf{c}$ chick in lateral view, $\mathbf{d}$, e chick in cranio-lateral view, f chick in caudo-palatal view (a)
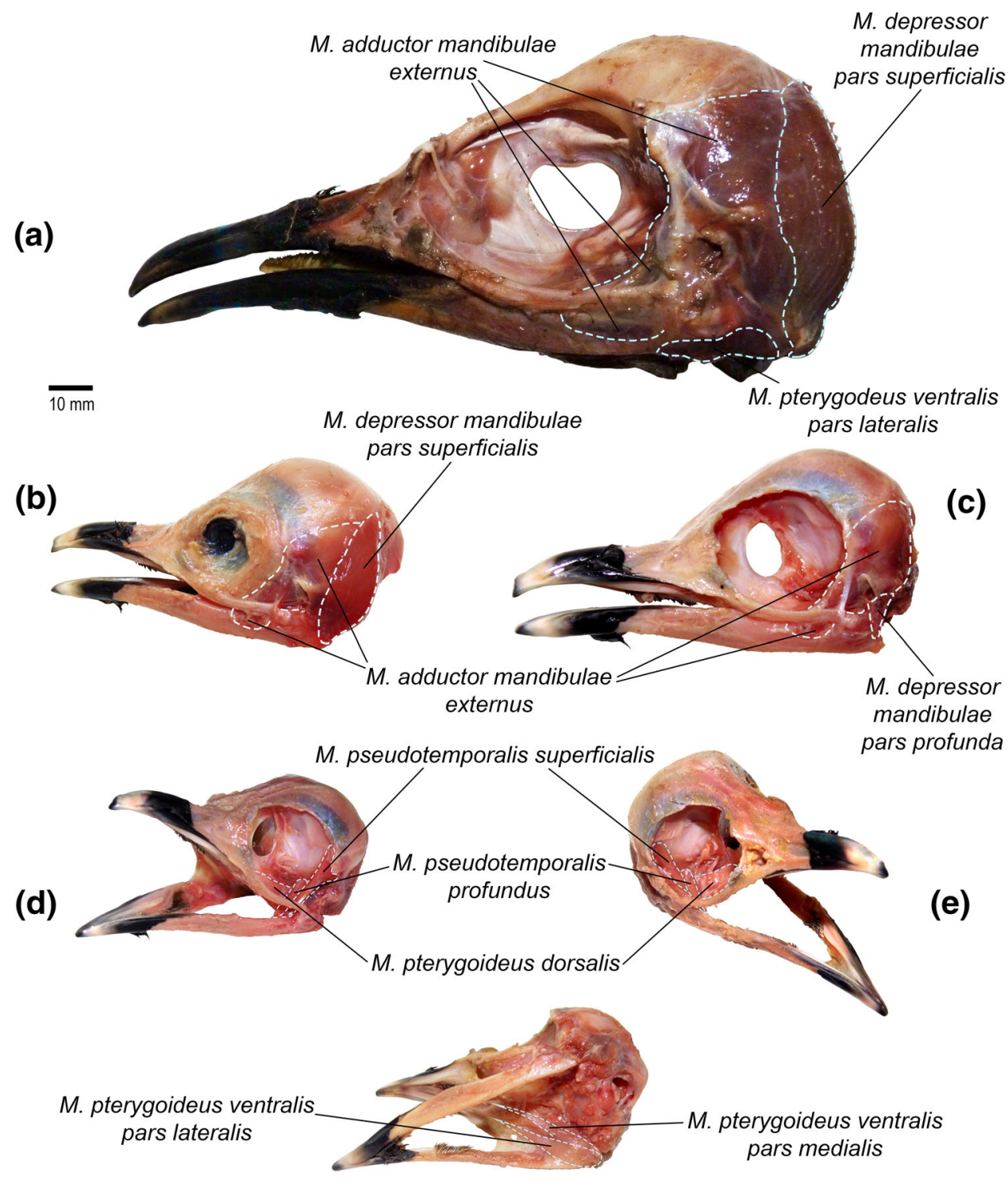

(f)
Musculus pterygoideus dorsalis

This muscle can be divided in two parts in chicks. The $M$. pterygoideus pars lateralis originates on the dorsal edge of the Os palatinum, while the M. pterygoideus pars medialis originates on the Os pterygoideum. Both parts are directed caudo-laterally to insert in the medial surface of the jaw, dorsal to its contact with the Os quadratum (Fig. 6d, e).

\section{Musculus protractor pterygoidei et quadrati}

This is a very small muscle in chicks. It originates on the caudoventral region of the septum interorbitalis and inserts into the posterior face of the corpus Os quadratum.

\section{Discussion and final remarks}

As expected, the development of the musculature is closely related to the degree of ossification of the skull and mandible. Cartilaginous structures hardly support muscle attachment. The following muscles were identified in all the ontogenetic stages analyzed: $M$. depressor mandibulae, M. adductor mandibulae externus, M. pseudotemporalis superficialis, M. pseudotemporalis profundus, M. pterygoideus ventralis, M. pterygoideus dorsalis, and M. protractor pterygoidei et quadrati. However, the development degree is clearly different in chicks, juveniles, and adults.

The $M$. depressor mandibulae is a voluminous muscle that occupies a large area on the back of the cranium. Although it is already defined in chicks, the proportional 
volume increases significantly in adults, which is coherent with their behavior because chicks are only fed by adults. The M. adductor mandibulae externus showed the greatest differences during postnatal ontogeny. It can typically be divided into three parts in adults: pars rostralis, pars ventralis, and pars profunda (Baumel et al. 1993). However, in chicks, it appears as a single and small muscle originated on the fossa temporalis and inserted on the mandible. Although each part remains still indistinguishable, this muscle is more voluminous in juveniles and occupies a larger area into the fossa temporalis, rostral to the origin of the M. depressor mandibulae pars superficialis.

The M. pterygoideus ventralis is clearly different in each stage. It is thin and inserts on the caudomedial surface of the mandible in chicks, whereas its volume increases in juveniles, in which the fibers reach the caudo-lateral surface of the mandible, to finally insert underneath the articulation with the Os quadratum. An increment in volume during growing is observed in the M. pseudotemporalis superficialis, $M$. pseudotemporalis profundus, $M$. pterygoideus dorsalis, and $M$. protractor pterygoidei et quadrati as the only visible change.

Crania of young chicks are weak, and ossification centers remain independent for each bone. Most of the elements complete their ossification and fusion with other bones during juvenile stages, whereas sutures between elements disappear partially or completely exclusively in adults.

The major osteological differences throughout ontogeny were found in the occipital region and the base of the cranium. These are the regions with the largest cartilaginous areas and unfused elements. The Os epioticum is independent and the degree of fusion with the $O s$ supraoccipitale is variable. The fusion is complete in juveniles, stage in which the foramen veni occipitalis externae is completed.

Maximum development of the prominentia cerebellaris is reached in adults, but an outstanding structure is already present in chicks. In juveniles, the prominentia cerebellaris already projects caudally beyond the condylus occipitalis.

The Os exoccipitale is completely fused with other occipital bones in juveniles and adults, but in chicks they remain separated at both sides of the foramen magnum. The condylus occipitalis is cartilaginous, small, and very poorly defined in chicks, acquiring the adult configuration in juveniles, except for the incisura mediana condyli that appears in adults.

Most of the surface of the fossa glandulae nasale is cartilaginous in chicks, constituting a slightly concave structure on the dorsal margin of the orbits. In juveniles, these fossae are better defined, although their caudal ends are not completely differentiated. Only in adults a well- marked medial rim differentiates each fossa from the $O s$ frontale. The fossa temporalis as well as the cristae occipitalis are only well defined in adults.

At the base of the cranium, chicks have the Os basioccipitale, Os exoccipitale, Os parasphenoidale, and rostrum parasphenoidale separated from each other. In juveniles these bones are fused and the general configuration is reminiscent of adults. The Os mesethmoidale is completely cartilaginous in chicks, and in juveniles it contributes to the formation of the septum interorbitalis.

The only element of the mandible that appears cartilaginous in chicks is the processus retroarticularis. All the other elements remain individualized. The cotylae are not completely differentiated in juveniles, and the tuberculum pseudotemporale is barely developed.

Finally, the proportions also change along postnatal ontogeny, particularly the relative extension of the bill and the globosity of the cranium. Chicks have more globous crania with shorter and deeper bills (at least at the base). In juveniles the bill reaches half of the length of the cranium, similar to the adult condition. The depth of the beak also increases with age, and the cranium loses globosity, becoming dorsoventrally depressed.

Acknowledgements We mainly thanks to the Instituto Antártico Argentino (Dirección Nacional del Antártico) for supporting the field trip. Dr. Leopoldo Soibelzon and Dra. Marcela Libertelli for the collected material, and Dr. Diego Montalti for the access to the material. María Florencia Sosa who improved the English grammar. To Julian Hume and two anonymous reviewers for their comments that improve the manuscript.

\section{References}

Baumel JJ, King JE, Breazile HE, Vanden Berge JC (1993) Handbook of avian anatomy: nomina anatomica avium, 2nd edn. Publications of the Nuttall Ornithological Club, Cambridge

BirdLife International (2012) Aptenodytes forsteri. The IUCN red list of threatened species 2012:e.T22697752A40172193. http://dx.doi. org/10.2305/IUCN.UK.2012-1.RLTS.T22697752A40172193.en. Accessed 21 Nov 2016

Cherel Y, Kooyman GL (1998) Food of emperor penguins (Aptenodytes forsteri) in the Western Ross Sea, Antarctica. Mar Biol 130:335-344

George JC, Berger AJ (1966) Avian myology. Academic, New York Isenmann P, Jouventin P (1970) Eco-éthologie du Manchot empereur (Aptenodytes forsteri) et comparaison avec le Manchot Adélie (Pygoscelis adeliae) et le Manchot royal (Aptenodytes paragonica). Expéditions Polaires Françaises

Jouventin P (1971) Comportement et structure sociale chez le manchot empereur. La Terre et la Vie 25:510-586

Klages N (1989) Food and feeding ecology of emperor penguins in the Eastern Weddell Sea. Pol Biol 9:385-390

Livezey BC, Zusi RL (2006) Phylogeny of Neornithes. Bull Carnegie Mus Nat Hist 37:1-544

Martínez I (1992) Order Sphenisciformes. In: del Hoyo J, Elliot A, Sargatal $\mathrm{J}$ (eds) Handbook of the birds of the world, vol 1. Ostrich to ducks. Lynx Edicions, Barcelona, pp 140-160 
Osa Y, Kuramochi T, Wataniku Y, Naito Y, Murano M, Hayama S, Orima H, Fujita M (1993) Application of computed tomography to morphological study of emperor and Adélie penguins. Auk 110:651-653

Prévost J (1961) Ecologie du manchot empereur. Expéditions polaires francaises. Hermann Press, Paris, pp 1-204

Saiff E (1976) Anatomy of the middle ear region of the avian skull: Sphenisciformes. Auk 93:749-759

Sclater PL (1888) Notes on the emperor penguin (Aptenodytes forsteri). Ibis 30:325-334

Stonehouse B. (1953). The emperor penguin (Aptenodytes forsteri, Gray): I. Breeding behaviour and development. (Vol. 6). HMSO, London
Welsch U, Aschauer B (1986) Ultraestructural observations on the lung of the emperor penguin (Aptenodytes forsteri). Cell Tissue Res 243:137-144

Wienecke BC, Robertson G (1997) Foraging space of emperor penguins Aptenodytes forsteri in Antarctic shelf waters in winter. Mar Ecol Prog Ser 159:249-263

Zusi RL (1975) An interpretation of skull structure in penguins. In: Stonehouse B (ed) The biology of penguins. Macmillan, London, pp 59-84 